\title{
Editorial
}

Jose Gustavo Prieto Munoz*, Annamaria Viterbo and Alberto Oddenino

\section{International Economic Law in the Era of Distributed Ledger Technology}

https://doi.org/10.1515/gj-2020-0037

Published online July 11, 2020

At the workshop on "International Economic Law in the Era of Distributed Ledger Technology" jointly organized by Gustavo Prieto, Annamaria Viterbo, and Alberto Oddenino which took place at Collegio Carlo Alberto, Turin, Italy, on 9th April 2019, selected authors from around the world presented their research into the impact of blockchain technology on international law.

We gratefully acknowledge the financial and logistical support from Collegio Carlo Alberto and the Law Department of University of Turin to organize the workshop. Our thanks also go to the kind academic support of the International Economic Law Interest Group of the European Society of International Law (ESIL) and all the participants and academics involved during the workshop, particularly to: Julie Maupin, who delivered an inspiring keynote on DLT; Catharine Titi, and Andreas Ziegler, for chairing the panels and contributing to the debate; and the editorial support of Luca Pes from the Global Jurist.

The motivation for this academic gathering was twofold, as detailed below. First, Bitcoin, the first cryptocurrency had been launched 10 years earlier, initiating a new era of decentralized computing thanks to the development of Distributed Ledger Technology (DLT), commonly referred to as "Blockchain". Over this decade, various legal disciplines sought to understand the financial impact of Bitcoin and other DLTs. However, the literature in international law remained silent regarding the potential impact of DLT technology on its various legal regimes. Thus, it seemed appropriate for us to reflect not only on what this

Article Note: This text was drafted during a Fellowship at the Law Department of the University of Turin (Project Dipartimento di Eccellenza MIUR 2018-2022).

*Corresponding author: Jose Gustavo Prieto Munoz, UNITO Department of Law, University of Turin, Turin, Italy, E-mail: jgprietomunoz@gmail.com

Annamaria Viterbo and Alberto Oddenino: UNITO Department of Law, University of Turin, Turin, Italy 
technology could do to improve the everyday practice of international lawyers, but also to examine the conceptual implications of DLT for the subfields of International Economic Law (IEL).

International law evolves as new developments impact entrenched rules; still, it can take a considerable amount of time to adapt to changes. This is true for many branches of law, but particularly so for international economic law. Treaties need to be negotiated, a process that can take several years to accomplish. These treaties then need to be approved by national legislatures. More recently, constitutional courts have also been actively involved in reviewing economic treaties. Thus, given the considerable amount of time since the advent of Bitcoin, it was worth asking how international law internalized DLT? How had lawyers and adjudicative bodies confronted the reality of adapting old rules to the latest developments? In this regard, we were especially curious as to how this tension between consolidated legal regimes and new technologies had unfolded for DLT.

Second, we saw this as a unique opportunity to use DLT as a mirror reflecting the current reality of international economic law. The idea was to inquire into the state of the different economic regimes-trade, investment, and financial-as well as the relevance of this methodological division to the study of economic transactions over the recent period. Is this triple division in international economic law still relevant for the discipline? Or would it be preferable to develop a new approach to international economic law, in general, better suited to grasping the new economic transactions as they unfold? The articles in this special issue intend to provide some methodological and substantive answers to these questions.

The opening article, "Crypto-investment in international economic law: A First Sketch", by Gustavo Prieto, takes on the methodological challenge of DLT technology for IEL by sketching possible conceptions of the technology in the discipline. The author first explores the conception of DLT as a digital "infrastructure" that aims, or at least claims to aim, at providing "trust" or managing distrust between economic actors. The technology thus represents a challenge from the normative point of view, because it requires adaptations to the concept of investment for the governance of DLT systems.

The second article, "Virtual currencies: New challenges to the right to privacy?", by Sara De Vido, examines how DLT, with a specific focus on Bitcoin, relates to instruments for human rights. The author highlights the tension between law and technology, stressing how the legal instruments in force cannot keep pace with DLT. A possible step forward would be moving towards a more flexible jurisdictional framework that could accommodate these tensions. The third article, "Bitcoin's identity crisis and the prospect of trustless money”, by Alain Zamaria, also focuses on the cryptocurrency "Bitcoin" as a case study that unfolds a discussion of the philosophy and governance underlying the idea of blockchain and DLT. 
He specifically examines how the inherent claim of decentralization in permissionless blockchains might be compatible with the centrality of trust in monetary relations.

The fourth article, "The disruptive effect of Distributed Ledger Technology and Blockchain in the over the counter derivatives market”, by Adolfo Paolini, adopts a different point of view for the analysis of the impact of DLT on financial transactions. He analyzes to what extent DLT may affect the way the "Over the Counter" (OTC) market operates, by providing investors with a trustworthy platform for the efficient assessment of risk. The author argues that DLT could indeed disrupt the financial derivatives market by making it more transparent, diverse, and more socially inclusive.

In the fifth article, "Challenges to the assessment of damages claims involving crypto-assets in investment arbitration”, Aveek Chakravarty turns his gaze to the impact of DLT on the international investment agreement (IIA) regime. He asks how the substantive legal protections shielding foreign investors from adverse host-State actions could soon become a forum for foreign investors. In particular, he studies the challenges faced by an arbitration tribunal in the process of valuing crypto-assets.

In the sixth article, "Adjudicating cryptocurrencies at the WTO: Potential threshold and substantive issues”, Sandeep Chandy and Prakhar Bhardwaj turn their attention to the impact of DLT on international trade law. The authors argue that DLT could result in forms of "crypto-trade", and therefore, is most appropriately covered by the GATS and its Annex on Financial Services. In the authors' opinion, any measure which imposes a ban on crypto-trade would adversely impact conditions for competition and lead to a violation of the most-favorednation and national treatment standards.

In the seventh article, "Will blockchain technologies strengthen or undermine the effectiveness of global trade control regulations and financial sanctions?”, Favio Cozzi approaches the study of DLT from the perspective of financial sanctions. In the current context of increasing restrictions and economic warfare between States, the author asks if blockchain solutions could interfere with the enforcement or compliance with sanctions, unpacking the different legal issues involved. The author concludes that lawmakers and developers should ensure that DLT will function as an instrument supporting a fair international system, rather than a tool to circumvent rules and undermine peace and security.

In the eighth article, "Enhancing e-commerce through Blockchain (DLTs): The regulatory paradox for digital governance”, Gustavo Guarín and Julián David Zuluaga analyze international economic and legal frameworks for the application of DLT in e-commerce. The authors argue that jurisdictions should not create new 
regulatory obstacles for innovation and the evolution of DLT applications in e-commerce. Furthermore, policymakers should adapt current regulatory frameworks to resolve some of the conflicts identified in the article. They also explore a principle-based approach that could help avoid overregulation of trade and lead to innovation in this field.

The last two articles in this special issue analyze two topics related to the development of new technologies in general. In the ninth article, "Narratives of the Digital Economy: How Platforms Are Challenging Consumer Law and Hierarchical Organization,” Alessandra Quarta, approaches the notion of digital platforms from the perspective of EU consumer law. She argues that the concept of 'platform' used in the digital economy creates 'short-circuits' in different legal regimes demanding new theoretical tools to cope with the challenges of post-industrial systems. In the final article, "Is Technology Really Inclusive? Some Suggestions from States Run Algorithmic Programmes”, Elisa Bertolini argues that without a proper system of legal remedies in the design of code and algorithms, technology will twist contemporary forms of state. The design of such legal remedies should consider the role of new technologies from the standpoint of the inclusiveness/exclusiveness dichotomy.

Altogether, the articles in this special issue offer different perspectives on the impact of DLT on economic transactions. At the same time, they show that the great tripartite division within International Economic law-trade, investment, and finance-still prevails. However, these branches have continued to become progressively more interconnected with each other and with other fields of international law. This scenario suggests that international economic lawyers will need to adapt not only by being open to new technologies, but also by developing the methodological skills to approach them holistically. 